\title{
Navigating an Uncharted Path: The Life and Legacy of Dr. Gladys B. West
}

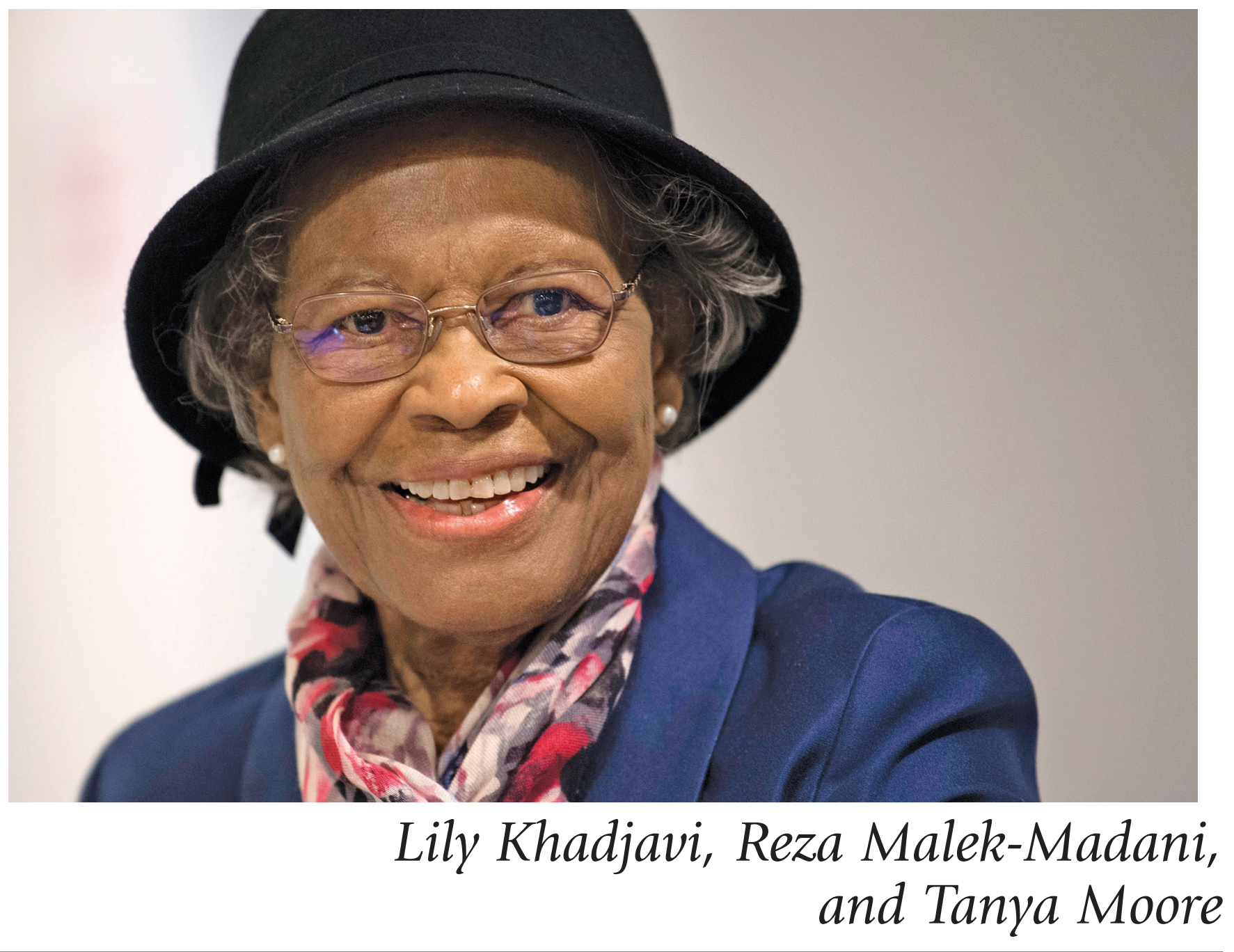

Lily Khadjavi is a professor of mathematics at Loyola Marymount University. Her email address is 1 khadjavi@1mu. edu.

Reza Malek-Madani is a professor of mathematics at the US Naval Academy. His email address is rmm@usna.edu.

Tanya Moore is founder of and managing partner at Intersecting Lines. Her email address is tanya@intersectinglines.us.

For permission to reprint this article, please contact:

reprint-permission@ams.org.

DOI: https://doi.org/10.1090/noti2243
In 2018, the Air Force recognized mathematician Gladys B. West with an Air Force Space and Missile Pioneers Award for her contributions over a career that spanned decades, from the first days of the space race. Notably, she had a hand in what is now a ubiquitous tool, the global positioning system. The use of satellite data to accurately assess position presents rich mathematical challenges, in part because of the difficulty in modeling the Earth itself. In awarding West, the Air Force noted her "increasingly refined calculations for an extremely accurate geodetic Earth 
model, a geoid, optimized for what ultimately became the Global Positioning System (GPS) orbit. Without that model, and regular updates thereto, the extraordinary positioning, navigation and timing accuracy of GPS would be impossible to achieve" [1]. The authors had an opportunity to interview West in August of 2020 to learn more about her experiences as a trailblazing mathematician. In this article, we provide a brief introduction both to West and to her mathematical contributions at the US Naval Surface Warfare Center.

West envisioned a life beyond her surroundings. At the closing of her interview with the authors, Dr. West said that, "mathematics creates a precise pathway" to finding solutions to many problems [3]. With conviction and precision, she used her vision and her mathematical skills as a compass to chart a path unlike any other she had seen. Her journey began simply with the dream of experiencing a life different than what she knew growing up on a farm in rural Virginia. As an African American girl born in 1930 at the beginning of the Great Depression, it was a bold desire. "I continued to dream beyond my wildest imagination, and no matter how inconceivable those dreams, I still had hope for a better life ahead," Dr. West explains in her memoir, It Began with a Dream [2]. Published in 2020, her autobiography chronicles her remarkable trajectory, as she became a pivotal contributor to a system that is now used worldwide. A high school geometry class gave her the first inkling that mathematics might be a part of the route to something different. "I was starting to realize early that this newly found love for geometry was something that could help me find that road I had dreamed about, the road that would take me far away from that farm," shares West [2].

\section{The Early Years}

During an era of Jim Crow in a segregated South, educational and professional opportunities for African Americans were limited, but West found clues and inspiration for her next steps from the people and environment around her. She found solace in her imagination and in simple moments like the melodic beauty of raindrops on the tin roof of her home during rainy days. "I always made the best of my days, though, by continuing to dream and imagine that I would be doing some other kind of work when I grew up" [2]. She had deep respect and admiration for her parents, in particular for her mother, Ma Macy, whose work ethic, organizational skills, and commitment to family and community made her a great role model in West's eyes. West says, "My mother worked part time, and one way of helping her was to learn new things and then do them too" [3]. But a labor-intensive life of working as a farmer was not a life she wanted for herself. West shares, "I remember my whole life struggling and planning and moving from one thing to another and wanting something more" [3]. When a fellow classmate, Dorothy Bates, a couple of years her senior, graduated from high school and continued on to college, she knew a college education was a possibility and aspired to do the same.

West attended high school at Dinwiddie Training School after completing the first years of her education in a single classroom school with one teacher. West earned top grades, in particular in her science and math courses, and was told by her teachers she was "college material." But with no way to afford college, it wasn't clear how she would achieve that goal. When she learned that the top senior in her high school was guaranteed a scholarship to college, she was motivated to earn that spot and successfully became valedictorian of her class. When it came time for her to select a college major she thought about what was most familiar to her. "Since I had been on the farm I probably was going to major in Home Economics, that's where I knew everything," says West [3]. Given her academic track record, however, her teachers urged her to consider math, a major they felt would be challenging and one that not all students could be successful pursuing. West reflects, "I knew that I liked the orderliness of math, the preciseness of it, the neatness of it. All of that fit my personality." West humbly ventured to say that she was good at math "not because I was so smart, but because I worked at it" [3]. These early years reveal the role of teachers in identifying and encouraging her interest in mathematics.

\section{College and Life-Changing Mentoring}

West attended Virginia State College (now University), a Historically Black College in Ettrick, Virginia. VSU was founded in 1882, during a period when over ninety HBCUs were founded, primarily in Southern states, to provide higher educational opportunities for freed descendants of African slaves in the US [4]. Already-established colleges and universities in the US would not be legally required to integrate until 1954 with the landmark ruling of Brown v. Board of Education. ${ }^{1}$ When asked about the role of HBCUs in educating Black students West says, "At the Black colleges you have more roots there...you have more of an opportunity to relate to more people who are affecting your life" [3]. While in college, West joined the sorority Alpha Kappa Alpha (AKA), the first sorority

\footnotetext{
${ }^{1}$ Even before Brown v. Board of Education, predominantly white institutions of higher education in the United States that had slowly opened their programs to Black and female graduate students in mathematics were not also open to hiring such faculty. In studying the history of these trailblazers-the first few Black men and women to earn PhDs in mathematics in the United States-it is easy to find mathematicians such as William Claytor or Evelyn Boyd Granville who, after postdocs elsewhere, took positions at HBCUs at least in part because predominantly white institutions refused to hire them. See Patricia Kenschaft's article "Black men and women in mathematical research" [14], for more on the paths of many of the first Black mathematicians in the United States.
} 
established for African American women. "You have Black colleges supporting sororities that brought Black people coming together to serve each other and the world," West reflects, "You have the feeling that you are there to help and dig in" [3]. This model of service and community would stay with her throughout her career. Interestingly, it was a fellow VSU alum and AKA who first shared the news of West's contributions to the development of GPS with the local press [2].

West also received life-changing mentorship from Professors John and Louise Hunter at VSU. The Hunters were remarkable in their own right. John Hunter was the third African American to earn a PhD in physics (Cornell University, BS in electrical engineering from MIT). ${ }^{2}$ Louise Hunter was the second African American and first African American woman to earn a doctorate from the University of Virginia, which was in the School of Education, after earning Bachelor's and Master's degrees in mathematics from Howard University. To West, they were the first model of a "power couple," and their relationship foreshadowed her long-time marriage and partnership with fellow mathematician Ira West. The combination of her hard work and their sage advice and guidance helped her to successfully navigate college. After her graduation in 1952, she taught high school mathematics, and then with the encouragement of the Hunters, she returned to earn her Master of Science degree in mathematics in 1955. She was beginning to teach high school again when an application resulted in a new job offer: a position as a mathematician conducting research for the Navy.

\section{Becoming a Mathematician for the US Navy}

The US Naval Proving Ground in Dahlgren, now the Naval Surface Warfare Center Dahlgren Division (Dahlgren), in Virginia, became the primary site of US Naval computing in 1948 (the year West had graduated from high school and three years after the end of WWII). After an executive order issued in 1955 by President Eisenhower that banned discrimination in Federal hiring practices, the door was open to hiring African Americans in Federal agencies. While the surrounding communities were still segregated (making dormitory housing on the naval grounds a necessity for Black employees), Gladys West credits her forward-thinking manager, Ralph Niemann, for opening the doors at Dahlgren to Black mathematicians. "He had great vision and foresight, bringing in those big computers, which required lots of mathematicians and scientists. Niemann believed that recruiting women and minorities into the workforce was one way to bring in people with very

\footnotetext{
${ }^{2}$ In 1971 Hunter-McDaniel Hall was built at VSU to house the science departments and was named in part for Dr. John M. Hunter who served as former head of the Physics Department, Director of the Graduate School, and Dean of the College [5].
}

strong skills who may have been overlooked elsewhere. At a time when so many were overlooking those who had looked like me, Niemann gave me a chance, the chance of a lifetime" [2]. ${ }^{3}$

But just because the doors were open at Dahlgren didn't mean it was a trivial endeavor to walk through those doors and stay. "We came to Dahlgren in the early 1950s, and we were the ones integrating the Naval Proving Ground. So we knew there would be a lot of hardships and discrimination we were going to face," recalls West [3]. Her commitment to the bigger picture of this opportunitynot just for herself but for those who would be coming after her-guided her steps. The work was challenging enough, but additionally, this was accomplished in a time of state-sanctioned segregation and a time when not many women could be found working in scientific or technical roles. West shares in her memoir, "I wanted to adapt to this fascinating, new environment and succeed as soon as I could. I knew my work was cut out for me. As a double minority like I was, at a time where opportunities for women and people who looked like me were scarce, I felt there would be a lot of folks counting on me. There were other women of color who were coming behind me, the Hunters, and my family back home, and I absolutely wanted to make them proud" [2]. Her mathematical abilities, coupled with her work ethic and mindset, positioned her to tackle the complex problems being explored at Dahlgren while navigating an environment where racial and gender barriers persisted. West became adept at converting challenges to fuel her motivation to excel during her 42-year career at Dahlgren.

\section{The Need for a Global Positioning System}

Dr. Gladys West's long and distinguished career as a mathematician at Dahlgren coincided with an unprecedented period of synergy between computational mathematicians and physicists. In the wake of the Russian launch of Sputnik, the Space Race had begun, and applications involving

\footnotetext{
${ }^{3}$ The critical importance of this theme, of women even having a chance, has been explicitly noted in the AMS Notices in Della Dumbaugh's article on Clare Boothe Luce. Luce recognized the value in women being able to pursue math ematics, science, and engineering with the creation of the Clare Boothe Luce Fund. Luce noted for herself, in regard to other pursuits, "I [would] just like to have had that kind of chance."

${ }^{4}$ Simply getting in the door is, of course, only a literal first step. It was in the very same period of time, in 1957, that federal troops were ordered to escort the Little Rock Nine in an effort to desegregate Little Rock Central High School, an iconic episode in US history, and it is well documented that the nine students suffered personal attacks while attending. Less known is that the nine students were officially barred from participating in any extracurricular activities, and that in the following year, all of the Little Rock high schools were closed in an attempt by segregationists to set back integration. Black researchers at Dahlgren were well aware of the civil rights movement, even if they may not have been in a position to participate, and West recalls in her memoir being moved to tears with other Black female colleagues when they saw photos in Ebony magazine of the students entering the school.
} 
satellites were inspiring new research frontiers. "We had some really high-powered physicists and engineers and all who would be working the equations," recalls West [3]. It is easy to imagine that determining location was of major interest, and the development of the global positioning system became a focus. Dahlgren was interested in determining how they could use satellite data to map as precisely as possible specific locations on the planet. This required geodesy, a branch of mathematics focused on estimating the shape of the Earth. For example, when geodesic circles are introduced to students, the Earth is often modeled as a sphere, or slightly better, as an ellipsoid because of flattening at the poles, but the reality is much more complex. To achieve a high level of precision, one which today we have come to take for granted from GPS readings on handheld devices, the Naval researchers had their work cut out for them. Even over water, where we might naively think that questions of topography were simpler, they had to incorporate the effects of tides, atmospheric conditions, and imperfect satellite readings over the ocean. It was necessary to understand the expertise of researchers dealing with all of these areas of physics and engineering. "They had [hired] mathematicians because they felt that we could adapt to the other sciences," says West [3].

These complex problems were being tackled just as computing technology was taking off. Dahlgren acquired the latest technology in computing, the Mark II and Mark III, which in the 1950s meant the Naval researchers had access to a computer which took up the size of a room, the most powerful one on the planet during that decade. ${ }^{5}$ By the late 1950s, IBM had built the Naval Ordnance Research Calculator (NORC) which was installed at Dahlgren. These machines were a remarkable contrast to the desktop calculators of the time. West notes, "It was completely new to us. We had never seen a big machine like that. All we had seen was a Marchant Calculator that sits on the desk" [3] which they used to compute range tables for ballistics. West had to create programs that would translate the scientific ideas into executable algorithms, coded in zeros and ones, which would be entered on punch cards by other staff members-indeed, it took a team of humans to implement this cutting edge technology once the mathematicians had done their work. "We had punch cards back in that day. We would write out what we wanted punched on the cards, and when we first began it was coded in zeros and ones. What you wrote up was given to the keypunchers to punch it out on the cards for you; they gave

\footnotetext{
${ }^{5}$ Such machines at Dahlgren were the descendents of Mark I, or IBM's Automatic Sequence Controlled Calculator. Programmed by leading researchers such as Grace Hopper, who had also come to the Navy in the 1940s, the Mark I was used by John von Neumann for military applications including the development of nuclear weapons. Hopper's career served as inspiration; West and other naval researchers were aware of her highly significant role in the development of computing, as well as her breaking of gender barriers.
}

it to another group to verify what was punched. Then it came back to you to put it in the tray, set it up, and it goes off to the computer where a whole group of operators access your punch cards. Sometimes they'd call you to see if you wanted to watch it, to see whether it blows up or it goes. That was old time; it's much easier now" [3]. Finding an error could mean combing through iterations of data in detail, unlike today's debugging where a specific error message may already point the way to the correction. West delighted in recalling a moment when she was able to pinpoint an error, "Thinking about the satisfaction of cracking the problem, finding the error, and also the team being excited about it, that was a nice moment" [3].

With the advent and availability of computers, and advances that contributed to the accurate modeling of physics at the speed of light, it became feasible to look at truly hard problems, ones that required precision in measurements as well as delicate computational modeling. Understanding Satellite Altimetry (SA), which measures the time taken for an electromagnetic (radar) wave or pulse to travel from a satellite to the sea surface and back, had resulted in new opportunities in military and scientific applications. It served as one of the core disciplines in Gladys West's mathematical efforts during the decades of the 1970s and 1980s. The results of these efforts ended up having significant military impact, but it also became an enabling factor that ushered in the current era of oceanographic studies from space.

\section{Tackling Positioning Data}

During a period of about a dozen years, Dr. West and her group at Dahlgren developed a successful mathematical and computational methodology to process radar altimeter observations. In a series of papers, which appeared between 1979 and 1986 (see references [6]-[9]), a set of intricate approaches and solutions were introduced and presented, which later also served as the backbone for the creation of GPS. In today's terminology, we refer to the type of problems that arise in SA and GPS as multiscale/multiphysics problems, whose modeling requires dealing with features with large variations in scales, both temporally and spatially, informed by data that is often very noisy and not directly related to the quantities being modeled. In processing SA data, one needs to take into account the effects of the atmosphere, ocean currents and tides, and the planet's rotation, among other features.

Satellite Altimetry is based on the seemingly simple notion that a wave's travel time reveals the distance it has travelled. While this notion is based on knowing the speed of the wave, which in this case is the speed of light, it is equally dependent on one's ability to measure accurately how a wave interacts with the medium it travels through. The bulk of West's work concentrated on recovering 


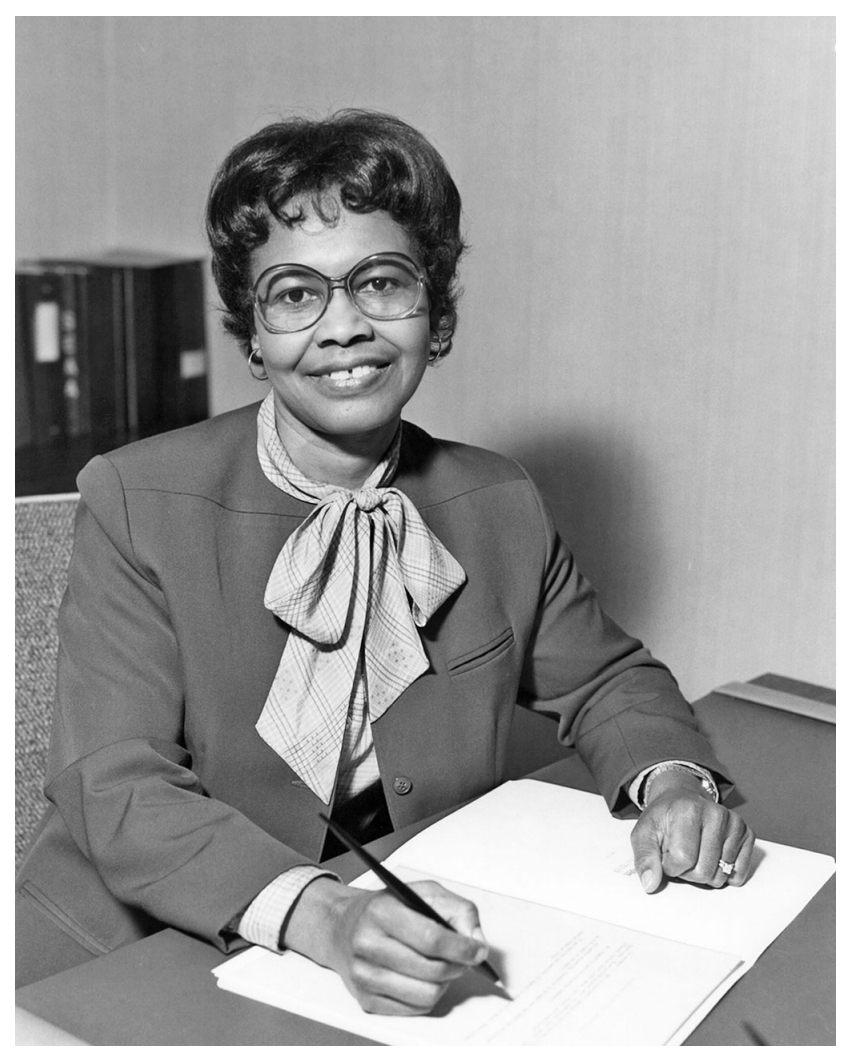

Figure 1. West at her desk in Dahlgren.

information about sea surface height measurements that were collected from a variety of satellites launched in the 1970 s and 1980s, with the goal of mapping anomalies in the geoid, anomalies due to a variety of parameters and forces, notably variations in density and bathymetry, and the impact of currents and tides in the oceans. As an aside, in the case of GPS, where typically one needs to measure distances from at least four satellites to accurately locate the position of a receiver, additional mathematical complications arise. Satellites move fast enough that the laws of special relativity are at play, and, as if that is not enough to deal with, the curvilinear nature of satellite orbits introduces the need for computations that can only be handled by taking into account general relativity effects. It cannot be overemphasized how much today's accuracy of locating our position to within a few meters owes itself to the computations that were pioneered and tested at Dahlgren many years before GPS became a reality.

As mentioned earlier, one of the applications that motivated Dr. West and her group at Dahlgren was to discover an accurate way to use SA data to describe the geoid, the equipotential surface of the Earth's gravity field. Identifying this surface, which is a good approximation of the mean sea level in the hypothetical case of no fluid motion in the oceans, is an old problem whose formulation has been addressed by many great mathematicians including Gauss, Stokes, and Laplace. If the Earth were a perfect sphere whose density depended only on radial distance, then its gravitational potential $\phi_{1}$ has the form

$$
\phi_{1}=\frac{G M}{r},
$$

where $G$ is the universal gravitational constant, $M$ is the total mass of the planet, and $r$ stands for distance. Additionally, the rotation of the planet about its axis induces the centrifugal acceleration $\boldsymbol{\Omega} \times(\boldsymbol{\Omega} \times \mathbf{r})$, where $\boldsymbol{\Omega}$ and $\mathbf{r}$ are the rotation and position vectors, respectively. The latter quantity has the potential $\phi_{2}$, that is,

$$
\boldsymbol{\Omega} \times(\boldsymbol{\Omega} \times \mathbf{r})=\nabla \phi_{2} .
$$

It turns out that $\phi_{2}=-\frac{1}{2} r_{\perp}^{2} \Omega^{2}$, where $r_{\perp}$ is the perpendicular distance to $\boldsymbol{\Omega}$ and $\Omega=|\boldsymbol{\Omega}|$. Therefore the idealized potential $\Phi$ is just the sum of $\phi_{1}$ and $\phi_{2}$ :

$$
\Phi=\frac{G M}{r}-\frac{1}{2} r_{\perp}^{2} \Omega^{2} .
$$

The geoid is a level surface of $\Phi$.

This derivation of the geoid is of course overly simplistic, a rough, first-order approximation of the real surface. In addition to Earth not being a perfect sphere, the density distribution over the planet causes anomalies whose structure is actually quite important for many applications. Figure 2 shows a sketch of a reference ellipsoid together with the geoid and its anomalies superimposed, and the various geometric quantities one must consider in a satellite measurement. The 2013 text by R. Sanso and M. Sideris [10] has a comprehensive introduction to geoid determination, ranging from various boundary-value problem formulations for the governing partial differential equations that are relevant for forward and inverse problems, to data-based techniques using satellite data that have become available since the Dahlgren efforts of the 1970s and 1980 s.

Returning to Dr. West's work, the group at Dahlgren did not have access to the computational frameworks that are available today and so they chose to address the problem of determining geoid anomalies directly by concentrating on the available satellite data at the time, data obtained from the Geodynamics Experimental Ocean Satellite (GEOS-3), SEASAT, and Geodetic Satellite (GEOSAT). These data were, on the one hand, noisy due to measurement errors that are very common in such systems, but more importantly, the data carried signatures of interactions with various atmospheric and oceanic phenomena that needed to be treated to get an accurate approximation of the mean sea level. As outlined in detail in [6] through [9], the Dahlgren team's approach of using a Kalman filter smoothing process based on a third-order Markov process (see [9], in particular) ended up being the right tool for processing the radar altimeter data. This led to highly accurate sea level altitude measurements, with less than 10 centimeters of error. 
The 1986 paper [9] contains the full story, the statistical algorithms, details of the GEOSAT data files, and the Kalman filter smoother. Among these major tools that are meant to deal with messy data, one finds an algorithm for computing the sea surface height $N_{i}$ (see Figure 2) from the radar altimeter data $h_{i}: N_{i}$ is the height of the geoid at time $t_{i}$, the average sea surface height above the reference ellipsoid that defines the hypothetical sea surface when the fluid is standing still, and $h_{i}$ is the measured distance from the satellite to the ocean surface, which is computed from data after painstaking corrections for atmospheric effects. Figure 2 shows a schematic of the position of the satellite, the reference ellipsoid $N_{i}$, and several other relevant quantities which will be introduced shortly [12].

It turns out that the determination of $N_{i}$ requires first finding $\phi_{i}$, the geodetic latitude, which is a solution of the equation

$$
\tan \phi_{i}=g\left(\tan \phi_{i}\right)
$$

where

$$
g(x)=\frac{1}{\rho_{i}}\left[z_{i}+\frac{a e^{2} x}{\sqrt{1+\left(1-e^{2}\right) x^{2}}}\right] .
$$

Here $\left(x_{i}, y_{i}, z_{i}\right)$ is the position of the satellite, $a$ is the mean radius of Earth, taken as 6378137 meters in [9], $\rho_{i}=$ $\sqrt{x_{i}^{2}+y_{i}^{2}}$ is the distance of the satellite to the polar axis of the ellipsoid, and $e$ is the eccentricity of the reference ellipsoid: $e=\sqrt{2 f-f^{2}}$ and $f=1 / 298.257223563 .^{6}$

Equation (1) is then viewed as a fixed point problem, and West applied an iteration algorithm that converged to the correct solution: beginning with an initial guess of $\tan \phi_{i}^{(1)}=\frac{z_{i}}{\rho_{i}}$, the iteration $\tan \phi_{i}^{(k+1)}=g\left(\tan \phi_{i}^{(k)}\right)$ is continued until the tolerance $\left|\tan \phi_{i}^{(k+1)}-\tan \phi_{i}^{(k)}\right| \leq \tau$, where $\tau=\left(1+\tan ^{2} \phi_{i}^{(k)}\right) 10^{-9}$, is achieved. Once $\phi_{i}$ is determined, one can compute the height $H_{i}$ since

$$
\sin \phi_{i}=\frac{z_{i}}{\eta_{i}+H_{i}},
$$

and $\eta_{i}$, the height of the reference ellipsoid above the equatorial plane, is given by

$$
\eta_{i}=\frac{a\left(1-e^{2}\right)}{\sqrt{1-e^{2} \sin ^{2} \phi_{i}}} .
$$

The quantity $N_{i}$, the desired sea surface height, is now determined from $N_{i}=H_{i}-h_{i}$.

Today, accurate measurement of sea surface height is one of the key tools in atmospheric oceanography and an important metric for measuring variability in the global climate. Subsequent to the earlier work at Dahlgren, the resulting accurate gravity models developed by the National

\footnotetext{
${ }^{6}$ For an excellent and accessible mathematical introduction to the various concepts in geodesy in general, and details about some of the notation in Figure 2, see the 1997 text by Gilbert Strang [11], Chapter 14.
}

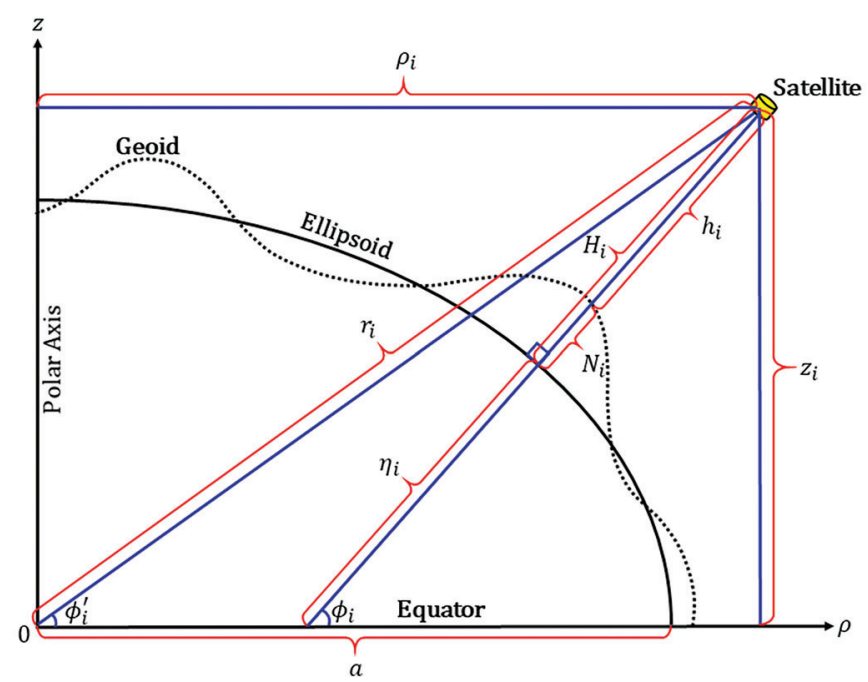

Figure 2. A sketch of a possible geoid and its reference ellipsoid.

Geospatial-intelligence Agency (NGA) and others are vital for military applications and for many commercial enterprises.

\section{Barriers and Breakthroughs}

While advances in GPS gained widespread utility once made public, research teams worked on a wide range of projects over West's 42 years at Dahlgren, the details of which were classified. Yet in the midst of these technological advances and the excitement of the progress being made on the work at Dahlgren, and regardless of the quality of their work, West and other Black mathematicians faced additional professional hurdles. "You can usually tell when something is happening 'cause there's a little feeling inside," West recalled [3]. We may be familiar with both the explicit indignities of Jim Crow and implicit biases that persist today, but many of these hurdles had cascading effects. A simple explicit example was the way in which racism affected the researchers' work travel. Because many hotels, especially in the South, operated as "Whites only," Black employees simply were not provided the same professional travel opportunities; this in turn limited professional development and the chance to lead projects, not to mention the opportunity to develop deeper ties with coworkers. Unsurprisingly, given that it was the 1950s, women were less likely to be considered for supervisory positions. West shared her perspective on how she navigated these workplace challenges, "We had come from an earlier place in which things were so poor, so scarce, and so having found this good job, we weren't going to run away from it just because someone turned their head [at us], you know?...There is a sort of downside but I guess I used it for inspiration purposes" [3]. 


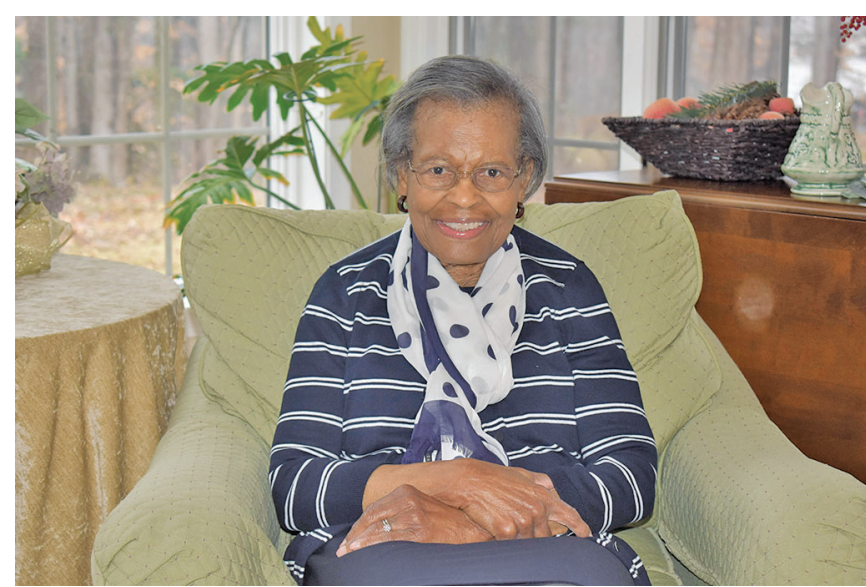

Figure 3. West at her home in Virginia in a photo taken by her grandson.

Nevertheless, over time West came to lead projects analyzing satellite data, including as a project leader for GEOS3, mentioned above, and, by the late 1970s, as a project manager for SEASAT [1]. Other work recognized by the Navy includes research in the early 1960s, when West and a small team of colleagues took advantage of the NORC and the new era of computational power to study the orbit of Pluto relative to Neptune, nicknamed "Project 29V," for which the group received a Naval achievement award.

In her memoir, West reflects on her mentor Louise Hunter's career, observing that Hunter, already a professor and with a Master's degree in mathematics, was driven to pursue a doctorate degree as well, becoming the first Black woman with a graduate degree from UVA. "It seemed like she still had something to prove, and maybe she felt like she was carrying the weight of other women on her shoulders. She probably wanted to be respected equally to the others in her profession, who were almost always men" [2]. Although West herself had already served as a leader in various capacities both at and even outside of work, as a school board member and as a member of the credit union board, she returned to school for a PhD in Public Administration, having earned a Masters in this field in 1973. Through an agreement with Virginia Tech and Dahlgren, she further continued her graduate work while working full time, and after her retirement, completed her dissertation, earning her doctorate in 2000.

\section{The Dream for the Next Generation}

There is much we can learn from West's life about pursuing dreams that may appear unattainable. Her legacy lies not only in her mathematical contributions but also in how she exemplifies life lessons such as persisting even in the face of challenges. It has been seventy years since West was first hired as a mathematician at Dahlgren, and yet many women today can still relate to the challenges of navigating mathematical environments in which they are the only one or one of only a few women present. How can this experience become the exception instead of the norm? We learn from West's life that her talent, discipline, and sense of teamwork learned during her early days helped her to persist in mathematics. Equally important was having teachers that recognized her abilities, mentors that guided her decision making, and employers who provided opportunities by giving her a chance. In the midst of her accolades and honors in recent years, she has retained a spirit of supporting and inspiring others by publishing her memoir and sharing her story with young people. Furthering her legacy, The Dahlgren Museum established The Ira and Gladys West Scholarship Fund [13], named after her and her husband of sixty-three years, Ira West. Donations will fund college scholarships for students in King George County, a rural area with many first-generation students and home to the Dahlgren base. Her life has made navigating the path towards a successful future a little easier for the next generation.

ACKNOWLEDGMENTS. The authors are grateful to Dr. Gladys West and her daughter Carolyn Oglesby for the opportunity to interview West. The authors also express their deep appreciation to Mr. Mark Storz, Chief, Space C2 and Sensors Analysis Branch, United States Space Force, for extended discussions of the technical material in this article and specifically for the creation of Figure 2.

\section{References}

[1] Air Force Space Command, Mathematician inducted into Space and Missiles Pioneers Hall of Fame, press release, retrieved on December 7, 2018, from https://www .afspc.af.mil/News/Article-Display/Article /1707464/mathematician-inducted-into-space -and-missiles-pioneers-ha11-of-fame/.

[2] Gladys B. West and M.H. Jackson, It began with a dream, IGWEST Publishing, 2020.

[3] Gladys B. West in discussion with the authors, August 2020.

[4] Tilden J. LeMelle, The HBCU: Yesterday, today and tomorrow, Education 123 (2002), 190.

[5] Shanesha R. F. Brooks-Tatum, Virginia State University preserves Black history with digital collections, Against the Grain 24 (2012), no. 1, Article 12, DOI:https://doi .org/10 $.7771 / 2380-176 X .6082$ accessed September 26, 2020.

[6] Gladys B. West, Smoothing of Geos 3 satellite radar altimeter data, J. Geophysical Research 84 (1979), no. 88, 40554066.

[7] Gladys B. West, SEASAT Satellite radar altimetry data processing system, NSWC Technical Report, NSWC TR 81-234, 1981.

[8] Gladys B. West, Mean Earth ellipsoid determined from SEASAT 1 altimetric observation, J. Geophysical Research 87 (1982), no. B7, 5538-5540. 


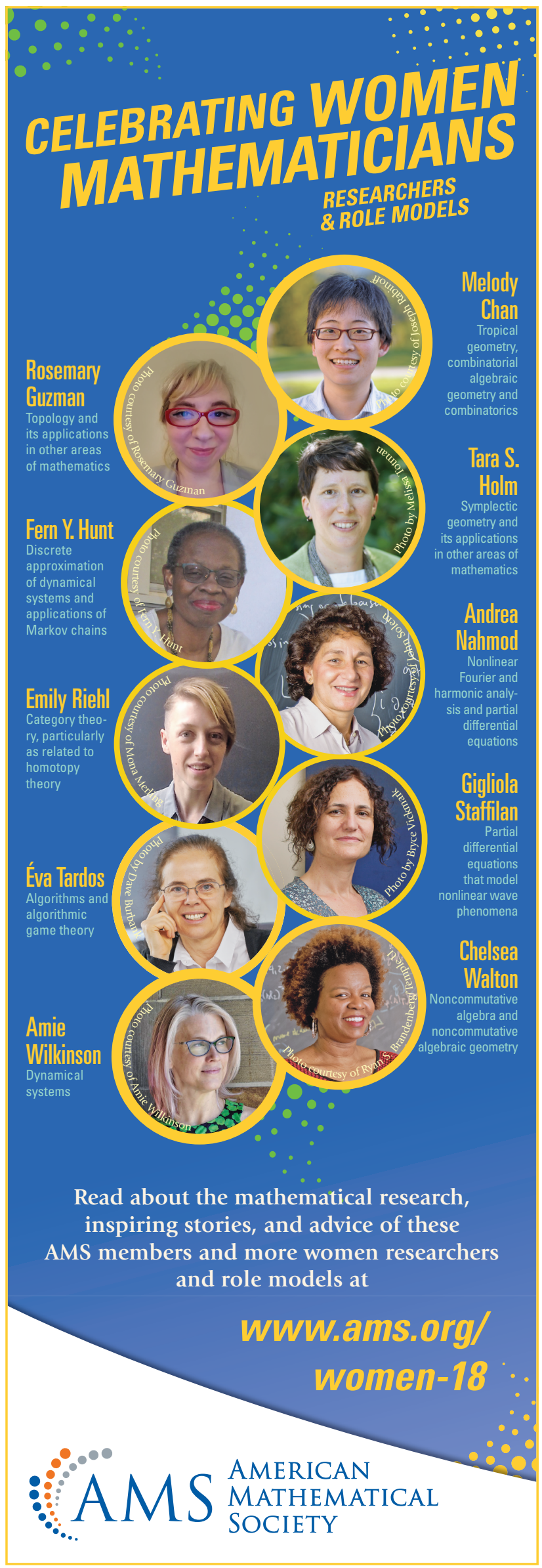

[9] Gladys B. West, Data processing system specifications for the system specifications for the GEOSAT satellite radar altimeter, NSWC Technical Report, NSWC TR 86-149, 1986.

[10] Michael G. Sideris, Geoid determination, theory and principles, Geoid Determination, Theory and Methods (Fernando Sanso and Michael Sideris, eds.), Lecture Notes in Earth System Sciences, Springer, 2013, pp. 356-362.

[11] Gilbert Strang and Kai Borre, Linear algebra, geodesy, and GPS, Wellesley-Cambridge Press, 1997.

[12] Mark F. Storz, Chief, Space C2 and Sensors Analysis Branch, Headquarters, United States Space Force, Operational Assessments Division, Private Communications.

[13] Ira and Gladys West Scholarship Fund.https://www .cfrrr.org/ira-and-gladys-west-scholarship -fund/.

[14] Patricia Kenschaft, Black men and women in mathematical research, J. Black Studies 18 (1987), no. 2, 170-190. www .jstor.org/stable/2784550.

[15] Della Dumbaugh, Creating opportunities and building confidence: Clare Boothe Luce's unexpected support of women in math and science, Notices Amer. Math. Soc. 66 (2019), no. 3, 387-394. MR3889351

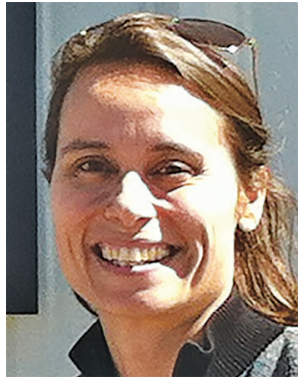

Lily Khadjavi

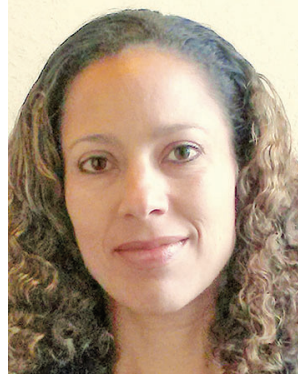

Tanya Moore

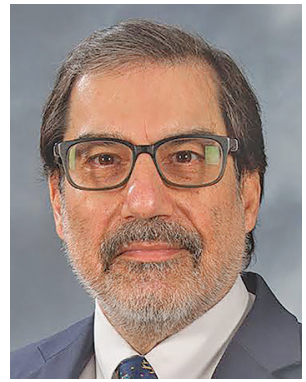

Reza Malek-Madani

Credits

The opening image and Figures 1 and 3 are courtesy of the West family.

Figure 2 is courtesy of Mark F. Storz.

Photo of Lily Khadjavi is courtesy of Lily Khadjavi.

Photo of Reza Malek-Madani is courtesy of Photo Lab: US Naval Academy.

Photo of Tanya Moore is courtesy of Tanya Moore. 